\title{
ANALYSIS OF DISPLACEMENT OF EXCAVATION BASED ON INCLINOMETER MEASUREMENTS
}

\author{
KAROLINA Gorska, MAREK WyJADŁOWSKI \\ Wrocław University of Technology, Faculty of Civil Engineering, \\ Institute of Geotechnics and Hydroengineering, Department of Engineering Foundations, \\ Wybrzeże Wyspiańskiego 27, 50-370 Wrocław, Poland, \\ e-mail: karolina.gorska@pwr.wroc.pl; marek.wyjadlowski@pwr.wroc.pl
}

\begin{abstract}
The article presents back analysis to estimate geotechnical parameters of fill layer. The agreement between field measurements and theoretical calculations was examined. Displacements of a cantilever CFA bored pile wall were monitored. The inclinometric measurements were taken directly after pile construction and according to excavation process. Over 200 calculation series were performed, with changing fill parameters. The calculations employed the actual geometric and material parameters of the pile wall, as well as geotechnical parameters of layered soil. The parameters estimated through back analysis were the angle of internal friction and Young's modulus of fill layer. In the case discussed, pile wall cap displacement was the response of the system, and soil medium parameters were the input data. The agreement between theoretical calculations and inclinometer measurements was assessed in accordance with two functions. The measured horizontal displacements of excavation support structure assumed different values at the two inclinometer sites analysed. Back analysis results for these sites are approximately convergent for a final excavation depth.
\end{abstract}

\section{INTRODUCTION}

Deep excavation supports should guarantee the security of any adjacent structures and underground infrastructure. Firstly, they should minimize displacements occurring in the process of deepening and expanding the excavation and while supporting the excavation walls. They are inspected by geodetic monitoring, which consists, first of all, in measuring displacements at points located in the adjacent engineering structures and in the excavation support top. These measurements enable evaluation of the size and range of excavation impact, as well as displacements of excavation supporting system - usually its top [10], [12]. A complete description of retaining wall displacements requires performing inclinometer measurements. They enable measuring horizontal displacements not only on the visible surface of the structure, but also below the excavation bottom, i.e., in the part beyond the reach of geodetic measurements.

The article presents basics of inclinometer measurements, the equipment used, methods of measurement casing installation and measurement performance [7]. In the case discussed, displacements of a cantilever CFA bored pile wall were monitored. The measurements were performed during excavation process. Geotechnical parameters of soil had been well recognized, except for uncontrolled fill. The procedure of determining internal friction angle and Young's modulus of uncontrolled fill layer employed back analysis of inclinometer measurements of pile wall horizontal dis- 
placements, as well as finite element method. This method has been successfully applied in [6]. The numerical calculations were performed with Plaxis 7.2 software using finite element method [14]. The choice of software was based on the possibility of calculating displacements along all the retaining structure, which is not enabled by most engineering software. The calculations employed the actual geometric and material parameters of the pile wall, as well as geotechnical parameters of layered soil.

\section{DESCRIPTION OF RESEARCH SITE}

Displacement measurements were carried out for a cantilever structure supporting a $4.0 \mathrm{~m}$ deep excavation. The excavation is supported by a vertical pile wall built of interlocking CFA bored piles with diameter $D=500 \mathrm{~mm}$. The $26.8 \mathrm{~m}$-long wall is composed of two sections with $21.2 \mathrm{~m}$ and $5.6 \mathrm{~m}$ in length. The plan of the wall is shown in Fig. 1. The length of a single pile $L=9 \mathrm{~m}$, while the axis-to-axis distance between piles is $400 \mathrm{~mm}$. Every other $\mathrm{C} 20 / 25$ concrete pile is reinforced with an IPE330 (S355) steel profile with $L=8.0 \mathrm{~m}$ in length.

The excavation was dug in two stages. In the first stage, it reached the depth of $2.0 \mathrm{~m}$ below ground level (July 2011). In the second stage, the planned excavation depth was reached (September 2011). After reaching the designed depth, the construction of bottom slab was immediately started.

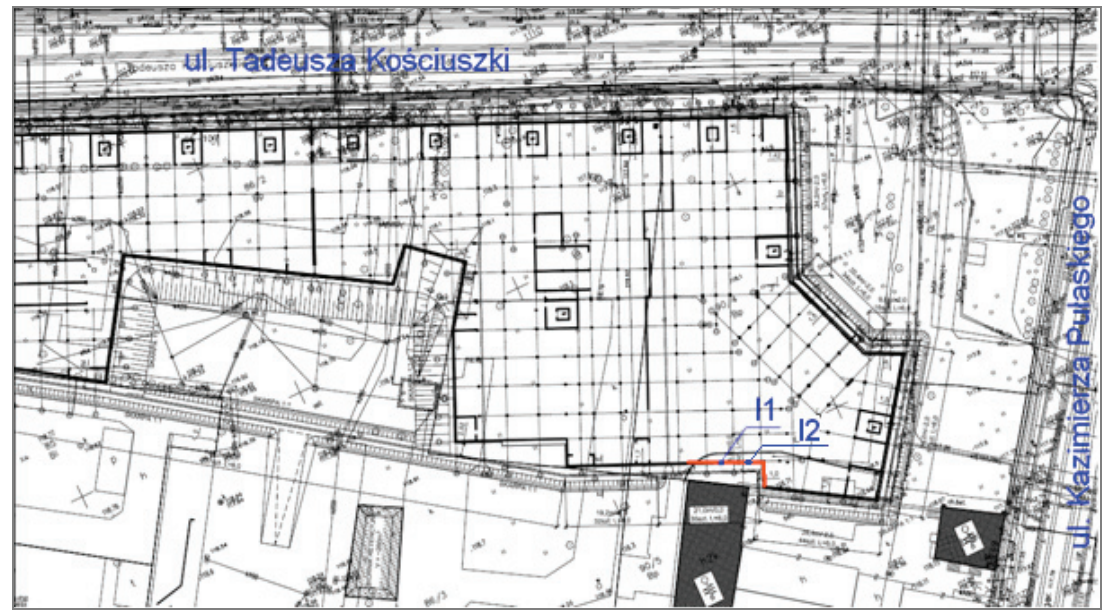

Fig. 1. Site plan - pile wall and exploration hole location

On the upper ground level above the excavation there is a building whose outer, load-bearing wall is supported on a $1.2 \mathrm{~m}$ wide mat foundation lying $1.2 \mathrm{~m}$ below ground level and $2.7 \mathrm{~m}$ away from the pile wall axis. A possibility of storing materials in the excavation impact zone was also assumed. 


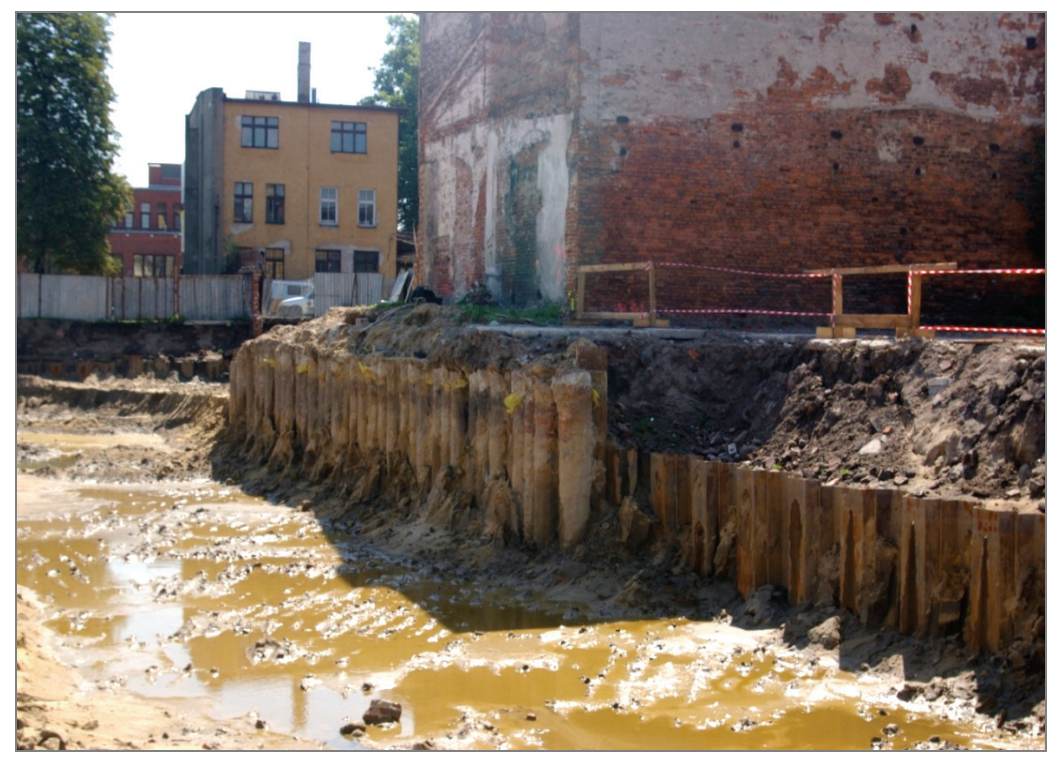

Fig. 2. Pile wall view

Inclinometer measurements were performed at two research sites, which had been prepared in the shoring structure. Inclinometer tubes, made of $50 \times 50 \times 3$ profiles were welded in sections to pile wall reinforcement (IPE330 profiles), and together with the reinforcement they were cemented inside the piles. The inclinometer tubes were $8.0 \mathrm{~m}$ long, which enabled measuring displacements down to the depth of $4.0 \mathrm{~m}$ below the excavation floor. The position of inclinometer tubes is shown in Fig. 2.

\section{INCLINOMETER MEASUREMENTS}

The inclinometer measurements were carried out with an inclinometer system produced by SISGEO. The system consists of an inclinometer probe, a dummy probe, an inclinometer cable and a data logger [9]. The inclinometer probe, in the form of a steel beam with two sets of wheels, is equipped with a measuring. It is lowered to the exploration hole on the inclinometer cable. The readings are recorded by the data logger. It allows wireless operation in the field, as well as previewing displacement graphs while the equipment is still on the measurement site.

The displacement measurement method is based on measuring the inclination angle of the inclinometer probe form vertical direction (Fig. 3). The measurements are performed on a stable level, which is enabled by copper rings crimped onto the cable. Horizontal displacement growths for each section are calculated from the following formula [5]: 


$$
\Delta u_{i j}=500 \mathrm{~mm} \times\left[\sin \left(\alpha_{i j}\right)-\sin \left(\alpha_{i 0}\right)\right]
$$

where: ment,

$\alpha_{i j}$ - probe inclination angle measured at the $i$-th section during the $j$-th measure-

$\alpha_{i 0}$ - probe inclination angle measured at the $i$-th section during the zero measurement (reference measurement).

In order to obtain a displacement growth at a given depth, one must add up the displacement growths for all the measurement sections below this point. Measurements are performed in four perpendicular directions, always clockwise starting from the "1st" direction. This allows defining the total displacements in two perpendicular directions.

Each measurement cycle starts from the zero measurement. It should be performed directly after preparing the exploration hole, with the aim of determining its original shape and orientation. Then successive measurements are carried out at time intervals depending on work progress on the building site. Each measurement should be started from the "1st" direction and then continued clockwise.
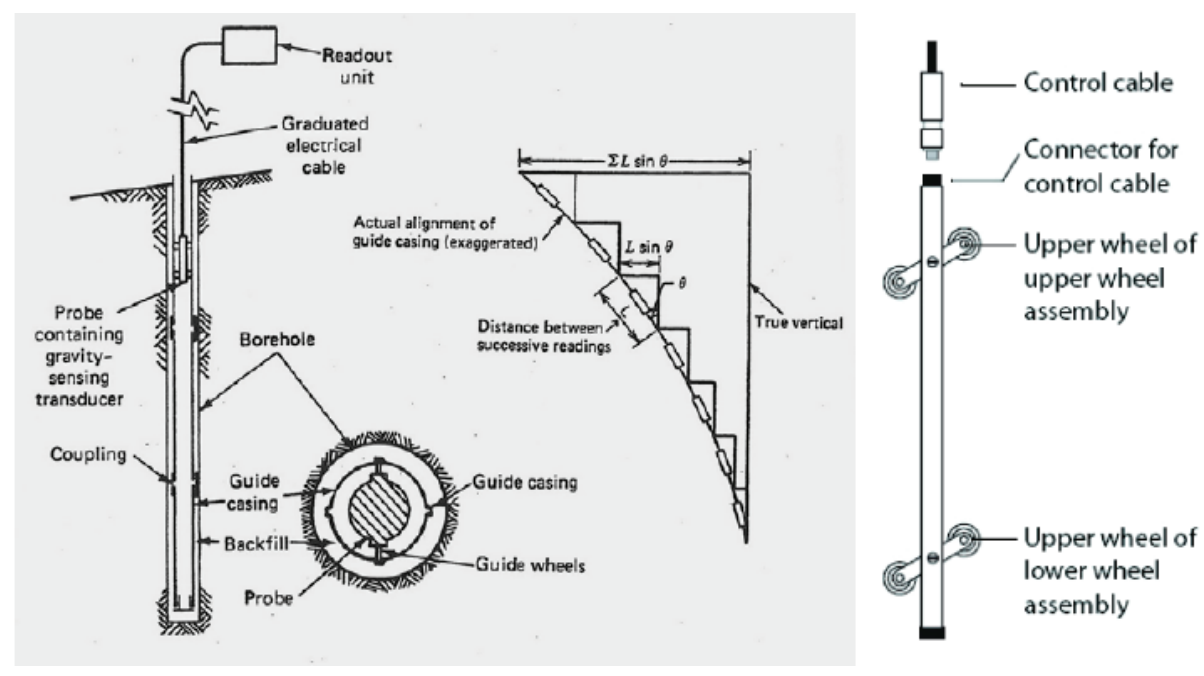

Fig. 3. Diagram showing measurement procedure

Measurement results are then processed with dedicated INCLI2 software [8]. This program allows the most common systematic errors to be corrected. There are four types of systematic errors: bias-shift, sensitivity drift, rotation error and depthpositioning error. For well experienced users identification and quantification is very easy. The bias-shift error is a small error within one data set and is caused by a shift in sensor calibration value " $b$ " between opposite traverses. The combination of casing inclination and sensor axis alignment shift produces rotation error. It is produced when 
the casing has been installed with an inclination in the cross-axis and occurs as a small shift in probe or sensor alignment. When significant casing inclination and vertical placement error occurs we should take into account depth-positioning error. The most common causes are change in probe depth or shortening of the casing. Those three errors can be easily corrected in program. The sensitivity error needs the reparation and calibration of probe.

a)

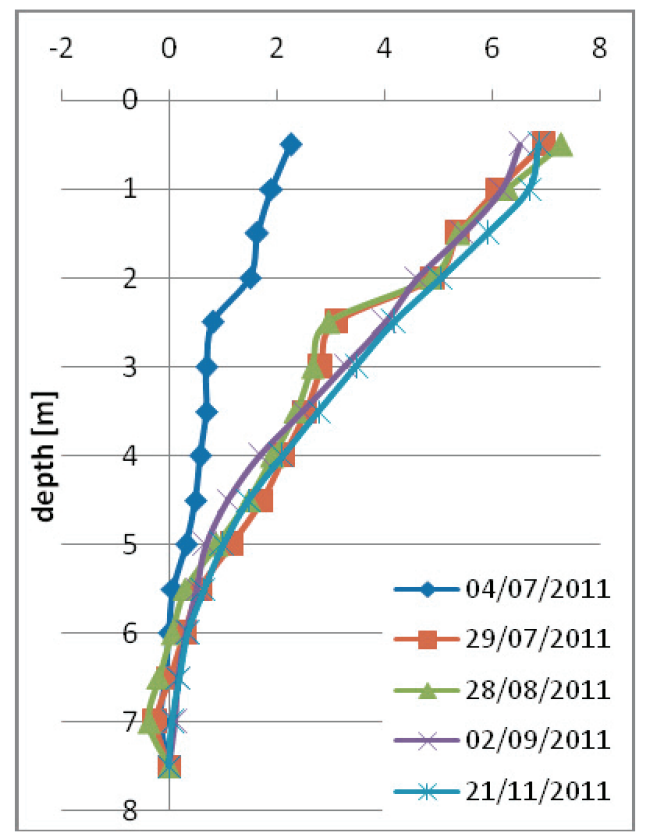

b)

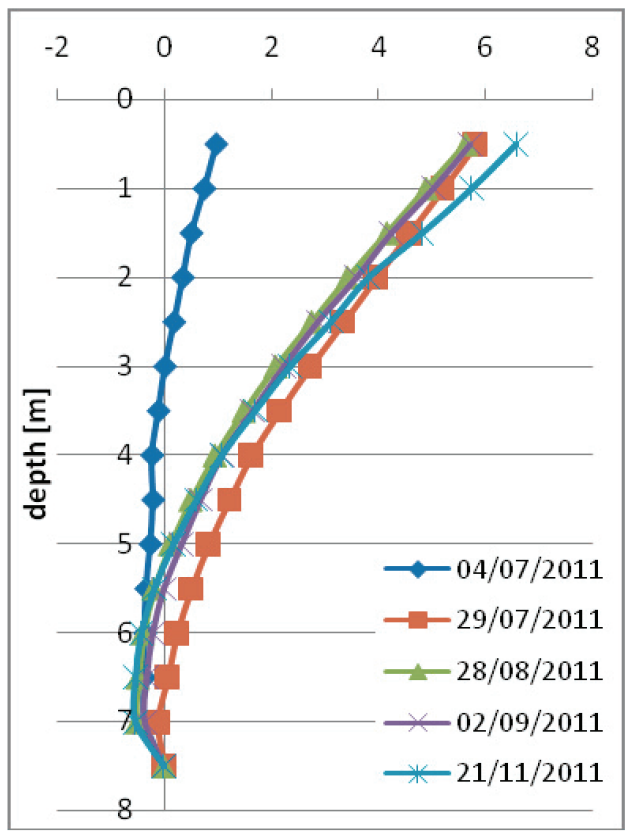

Fig. 4. Displacements towards the excavation. Measurement sites: a) I1, b) I2

The zero measurement was carried out directly after pile construction. The first measurement was taken for excavation depth of $2.0 \mathrm{~m}$. The displacement of the wall top was $2 \mathrm{~mm}$ and a bulge was noticed in the wall near the excavation floor. As this excavation depth was left unchanged for the next month, additional measurements were taken on 29th July and 28th August. These measurements demonstrated distinct displacement growths occurring briefly after the previous measurement, followed by stabilization (crown displacement by $6.38 \mathrm{~mm}$ ). The exposed part of the pile wall was additionally displaced. For measurement site I1, one can clearly observe pile wall fastening in the soil below the excavation floor. The next measurement was performed after reaching the designed excavation depth. The final measurements (21.11) displayed stabilization of displacement. The values of pile wall top displacement were slightly lower than those predicted at the stage of design calculations. 
On site I2, measurements were taken on the same days as on site I1. The observed displacements were slightly lower than those on site I1. At the first stage of digging, no significant wall bulging was observed at excavation floor level.

What is characteristic for both research sites is a significant $(1.5 \mathrm{~mm})$ displacement at the base of the retaining structure. Inclinometer measurements assume fixity of the bottom of the measurement casing, so all the graphs demonstrate zero displacements at the bottom, which is at variance with the actual displacement of the structure over time. At the measurement point located $0.5 \mathrm{~m}$ higher, the graphs diverge. This points to the displacement of the whole wall, which has been confirmed by numerical calculations and is related to horizontal and vertical displacement of the excavation floor (Section 5.2). To ascertain indisputably the movements of the structure, geodetic measurements of the measuring casing head are necessary. In this case, such measurements were not carried out.

\section{SOIL-WATER CONDITIONS}

The pile wall is embedded in layered geotechnical soil. The surface layer is made up of $2.0 \mathrm{~m}$ thick uncontrolled fill. The fill contains sands, sandy clays, bricks, gravel, stones, topsoil and rubble. Below there are native soil (Table 1). The first $2.0 \mathrm{~m}$ thick layer consists of medium/coarse-grained sands with density index $I_{D}=0.60$. Under 4.0 $\mathrm{m}$ below ground level there are cohesive soils. These are sandy clays whose plasticity index decreases with depth.

Table 1

Geotechnical parameters

\begin{tabular}{|l|c|c|c|c|c|c|c|}
\hline \multirow{2}{*}{ Soil type } & Thickness & $I_{D} / I_{L}$ & $\gamma$ & $E$ & $v$ & $c$ & $\phi$ \\
\cline { 2 - 8 } & $\mathrm{m}$ & - & $\mathrm{kN} / \mathrm{m}^{3}$ & $\mathrm{MPa}$ & - & $\mathrm{kPa}$ & $\circ$ \\
\hline Uncontrolled fill & 2.0 & - & $18.0 / 21.0$ & 10 & 0.3 & 0 & 28 \\
\hline Medium/coarse-grain sand & 2.0 & 0.60 & $18.5 / 19.5$ & 94 & 0.25 & 0 & 34 \\
\hline Sandy clays 1 & 1.0 & 0.29 & $20.5 / 20.5$ & 21 & 0.3 & 26 & 15.5 \\
\hline Sandy clays 2 & 1.0 & 0.10 & $22.0 / 22.0$ & 50 & 0.3 & 44 & 23 \\
\hline Sandy clays 3 & - & 0.09 & $21.5 / 21.5$ & 50 & 0.3 & 50 & 25 \\
\hline
\end{tabular}

\section{COMPUTATIONAL ANALYSES OF PILE WALL STRUCTURE}

Computational analyses of the bored pile wall displacements were carried out at the design stage and as back analysis after the structure completion.

In practice, three kinds of static analyses of excavation support can be distinguished [10], [12]:

- classic methods, where the excavation support is modelled as a rod system loaded with active and passive earth pressure, 
- calculating excavation support as a statically indeterminate structure loaded with earth pressure and an unknown response of the bedrock modelled by means of a spring analogue,

- static analysis of a planar structure, composed of the retaining structure and the interacting soil mass, carried out with finite element method.

The latter method enables calculating displacements of the shoring structure and the surrounding soil medium. It is recommended for back analysis of the structure. The rudiments of back analysis have been described in [1]-[3], [13], [15] and [16].

Back analysis is one of the most accurate methods of determining the values of geotechnical parameters when the results of field or laboratory measurements are known. Back analysis is a group of numerical methods, which consist in looking for such values of geotechnical parameters for which numerical calculations would give results corresponding to displacements or stresses that are observed at the existing sites or structures. The convergence test is described by the assumed objective function. In the search algorithm, the value of this function is minimised. Typically, the objective function is the sum of the smallest squared differences between the values measured during the experiment and the computational ones. The computational values are obtained through FEM analyses or other computational methods where the sought material parameters are employed as model variables. Back analysis can be carried out as deterministic analysis or it can be related to probabilistic methods [11].

\subsection{PRELIMINARY DESIGN CALCULATIONS}

In order to check pile wall stability, Blum's method was used to perform design stage calculations for characteristic values of geotechnical parameters.

The adopted parameters included active earth pressure load from the total unit weight of soil, loads at the upper ground level and service load. Below the groundwater table, bulk density of soil reduced by the impact of water uplift was adopted, allowing for the hydrostatic pressure of groundwater. The adopted passive earth pressure on the excavation side was reduced by coefficient $\eta_{p}=1.3$. Constant characteristic upper ground level load of $10 \mathrm{kPa}$ was adopted for all the surface. A $180 \mathrm{kPa}$ strip load from the existing building, with the width of $1.2 \mathrm{~m}$, was adopted at a distance of $2.70 \mathrm{~m}$ from the pile wall.

Horizontal displacement $u=8 \mathrm{~mm}$ of pile wall top was calculated for the excavation depth of $4.0 \mathrm{~m}$. These calculations were used to create the pile wall described in Section 2.

\subsection{NUMERICAL CALCULATIONS}

The theoretical analysis included developing a computational model and performing finite element method calculations. A computer simulation took into account pile wall construction, all the stages of excavation digging and gradual lowering of water 
table in the excavation. The calculations were performed with PLAXIS v. 7.2. software [14] employing finite element method.

The adopted soil medium allowed for all soil layers and stabilizing groundwater level. Depending on the work stage, various groundwater table levels were adopted. Table 1 contains isotropic parameters used in elasto-plastic calculations for CoulombMohr model and non-associative law of plastic flow. Soil parameters were adopted in line with geotechnical documentation. Typical triangular six-node finite elements were employed in soil modelling. The pile wall was modelled as a beam element with strength parameters: $\mathrm{EA}=14.53 \mathrm{GN} / \mathrm{m}, \mathrm{EI}=875 \mathrm{MNm}^{2} / \mathrm{m}$. No groundwater flow below the pile wall was assumed.

Over 200 calculation series were performed, with changing parameters. The angle of internal friction ranged from 24 to $36^{\circ}$, while Young modulus - from 40 to $120 \mathrm{MPa}$. Calculation results for parameters $\phi=27^{\circ}$ and $E=90 \mathrm{MPa}$ are shown below.

Figure 5 shows total displacements (deformed mesh) for parameters $\phi=27^{\circ}$ and $E=90 \mathrm{MPa}$. Deformations in the direction of excavation can be observed, accompanied by significant rebound of excavation floor. These phenomena result in a displacement of the bottom of the retaining structure and they are also observed in inclinometer measurements (Section 3).

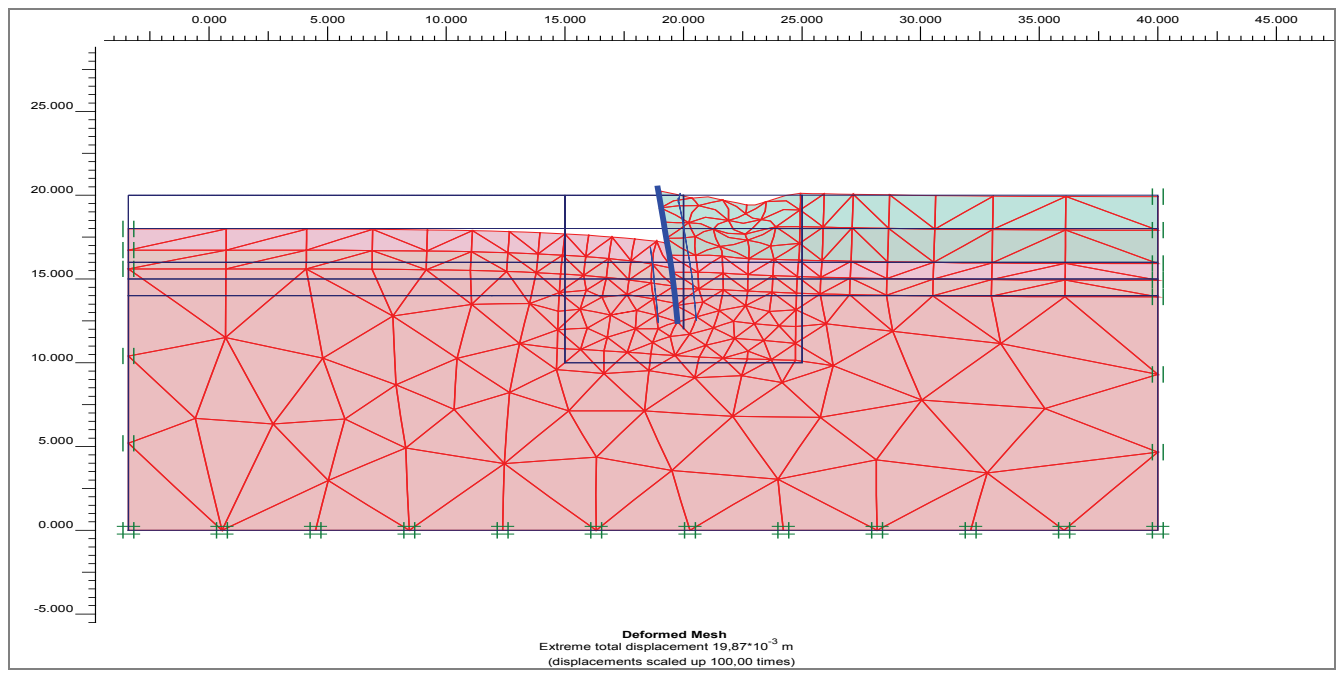

Fig. 5. Total displacements (deformed FEM mesh) - excavation depth of $4.0 \mathrm{~m}$

Figure 6 shows a disturbance in the range of direct excavation impact zone, which is $0.5 \mathrm{H}$ for non-cohesive soils and $0.75 \mathrm{H}$ for cohesive soils [4]. The observed disturbance is of more local character and is related to the load transferred by the footing of the building situated on the upper ground level. 


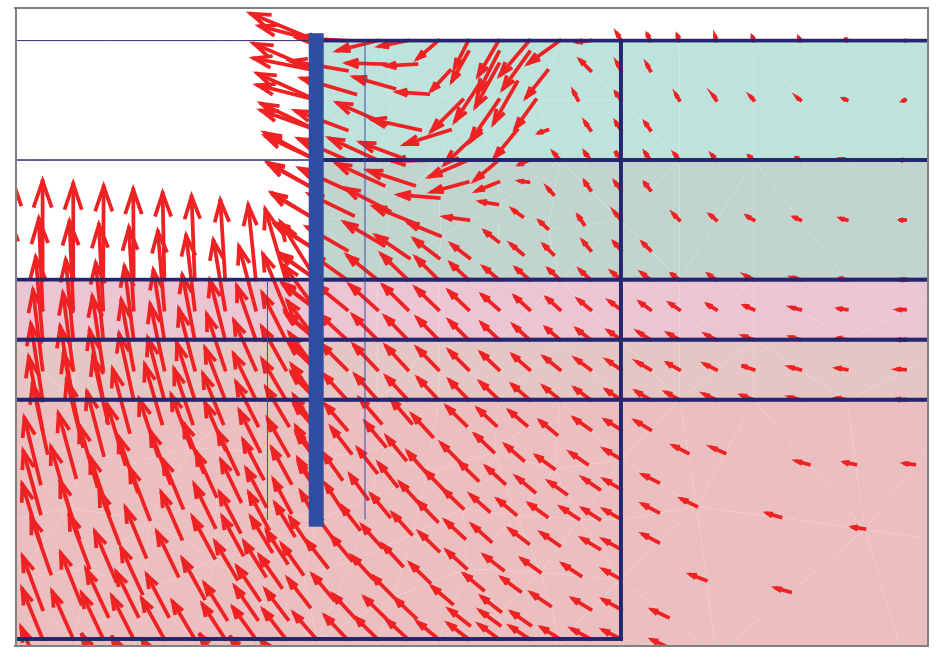

Fig. 6. Total displacements (displacement directions) - for excavation depth of $4.0 \mathrm{~m}$

\subsection{BACK ANALYSIS}

In order to identify the geotechnical parameters of fill layer, back analysis was performed with horizontal displacement of pile wall used as the leading parameter. The parameters estimated through back analysis were the angle of internal friction and Young's modulus of fill layer.

In the case discussed, pile wall displacement was the response of the system, and soil medium parameters were the input data.

The values of the sought geotechnical fill parameters were defined by minimising the sums of squared differences between the calculated quantities of theoretical displacements $U_{i}$ and the measured displacements $\hat{U}_{i}$.

The agreement between theoretical calculations and inclinometer measurements was assessed in accordance with function (2) equation

$$
\Psi_{1}=\sum_{i}^{n}\left(U_{i}-\hat{U}_{i}\right)^{2}
$$

for the set of $n$ data: $\left(U_{i}, X_{i l}\right), i=1,2, \ldots, n, l=1,2, \ldots, m . X$ is the vector of $U$ function arguments, i.e., the angle of internal friction and Young's modulus.

Based on numerical calculations, a growth in pile wall displacement in datum range: $0.5 \div 4.0 \mathrm{~m}$, was adopted as $U_{i}$ value. $0.5 \mathrm{~m}$ is the datum of inclinometer measurement at pile wall cap and $4.0 \mathrm{~m}$ is the excavation floor level.

$$
U_{i}=U_{i ; 0,5}-U_{i ; 4,0} \text {. }
$$


In another version of back analysis calculation, the value of function $\Psi_{2}$ was the difference between displacement increments in datum range $0.5 \div 4.0 \mathrm{~m}$, at $0.5 \mathrm{~m}$ intervals

$$
\Psi_{2}=\sum_{i=0,5}^{3,5}\left[\left(U_{i}-U_{1+0,5}\right)-\left(\hat{U}_{i}-\hat{U}_{i+0,5}\right)\right]^{2} .
$$

In functions (2) and (3), the adopted values of relative displacement $\hat{U}_{i}$ were based on inclinometer measurements, although they do not represent the actual deflection curve of the pile wall.

Two stages of excavation digging were analysed: excavation to the depth of $2.0 \mathrm{~m}$ and $4.0 \mathrm{~m}$. Initially, the lower range boundary for angle of internal friction $\Phi=29^{\circ}$ was taken into account, like for very loose non-cohesive soil. For this parameter range, the minimum for $\Psi$ function (2) was not obtained inside the assumed range, but on its lower boundary. Therefore, FEM calculations were performed for the angle of internal friction range $\Phi=24 \div 36^{\circ}$ and Young's modulus range $E=40 \div 120 \mathrm{MPa}$.

Table 2

Inclinometer measurement results and values of functions $\Psi_{1}$ and $\Psi_{2}$

\begin{tabular}{|c|c|c|c|c|}
\hline & \multicolumn{4}{|c|}{ Relative displacement [mm] } \\
\hline \multirow[t]{2}{*}{ Depth } & \multicolumn{2}{|l|}{ Site I1 } & \multicolumn{2}{|l|}{$\begin{array}{r}\text { Site I2 } \\
\end{array}$} \\
\hline & Stage 3 & Stage 4 & Stage 3 & Stage 4 \\
\hline 0.5 & 0.64 & 6.38 & 0.96 & 5.70 \\
\hline 1.0 & 0.75 & 5.89 & 0.74 & 5.01 \\
\hline 1.5 & 0.84 & 5.22 & 0.50 & 4.23 \\
\hline 2.0 & 0.83 & 4.57 & 0.34 & 3.58 \\
\hline 2.5 & 0.09 & 4.14 & 0.18 & 2.86 \\
\hline 3.0 & 0.08 & 3.51 & 0.01 & 2.23 \\
\hline 3.5 & 0.15 & 2.82 & -0.11 & 1.65 \\
\hline 4.0 & 0.01 & 2.12 & -0.23 & 1.08 \\
\hline$\hat{U}$ & 0.00063 & 0.00426 & 0.00119 & 0.00462 \\
\hline$U$ & - & 0.00419 & - & 0.0030 \\
\hline \multicolumn{5}{|c|}{ Parameters estimated by back analysis for excavation $h=4.0 \mathrm{~m}$} \\
\hline$\Psi_{1}$ & \multirow{2}{*}{$\Phi=27^{\circ}, \mathrm{E}=60 \mathrm{MPa}$} & $4.4 \mathrm{E}-9$ & \multirow{2}{*}{$\Phi=25^{\circ}, \mathrm{E}=50 \mathrm{MPa}$} & $2.89 \mathrm{E}-13$ \\
\hline$\Psi_{2}$ & & $7.23 \mathrm{E}-8$ & & $2.93 \mathrm{E}-8$ \\
\hline
\end{tabular}

The back analysis was based on the results of inclinometer measurements from sites I1 and I2. For site I2 and excavation depth of $4.0 \mathrm{~m}$, the values of functions $\Psi_{1}$ and $\Psi_{2}$ shown in Figs. 7 and 8 were obtained. The graphs present function values for different angles of internal friction and Young's modulus arguments.

For site I2, relative displacement $\hat{U}$ between values 0.5 and $4.0 \mathrm{~m}$ is larger than for site I1. Consequently, geotechnical fill parameters estimated by back analysis are worse for site I2. 
Results of functions $\Psi_{1}$ and $\Psi_{2}$ for site $\mathrm{I} 2$ and excavation depth of $4.0 \mathrm{~m}$ are shown in Figs. 7 and 8. The minima for functions $\Psi_{1}$ and $\Psi_{2}$ were obtained for the angle of internal friction $\Phi=24^{\circ}$.

The minima for functions $\Psi_{1}$ and $\Psi_{2}$, for inclinometer site I2, were obtained for angle $\Phi=25^{\circ}$.

For inclinometer I1 and excavation depth of $4.0 \mathrm{~m}$, the results shown in Figs. 9 and 10 were obtained. The minima for functions $\Psi_{1}$ and $\Psi_{2}$ were obtained for angle of internal friction $\Phi=27^{\circ}$.

The influence of Young's modulus on the values of functions $\Psi_{1}$ and $\Psi_{2}$ for all the range of the analysed angles of internal friction is very small.

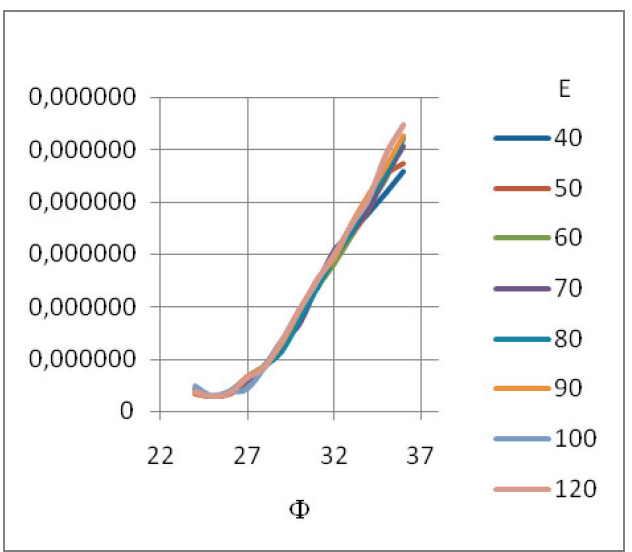

Fig. 7. Graphs of $\Psi_{1}$ function values, site I2

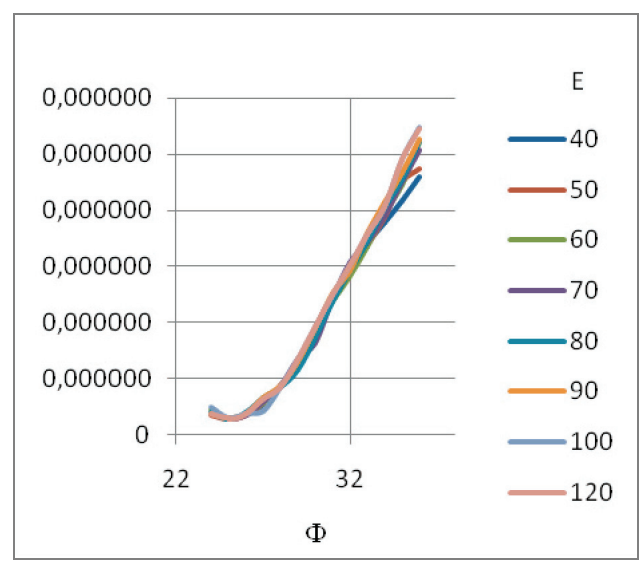

Fig. 9. Graphs of $\Psi_{1}$ function values, site I1

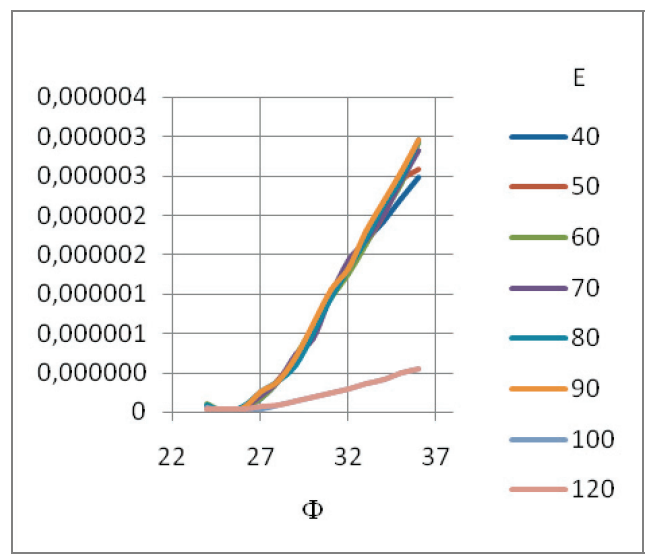

Fig. 8. Graphs of $\Psi_{2}$ function values, site I2

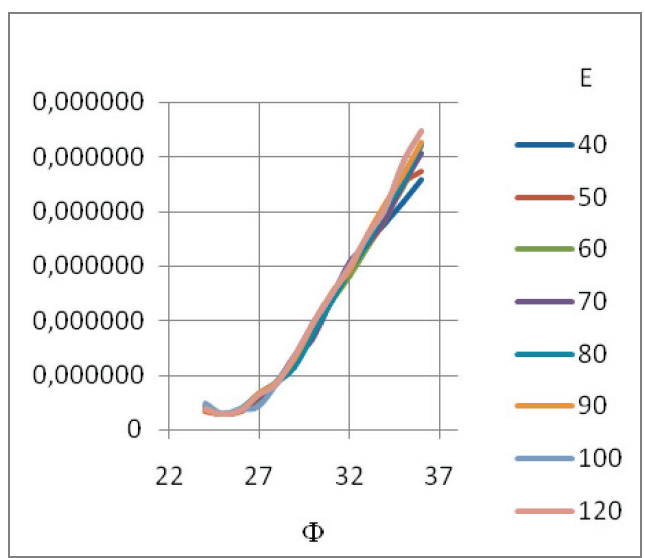

Fig. 10. Graphs of $\Psi_{2}$ function values, site I1 


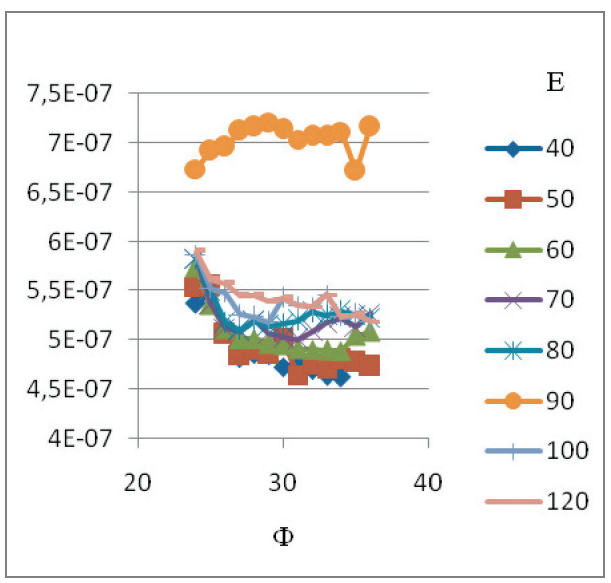

Fig. 11. Graphs of $\Psi_{1}$ function values, site I2

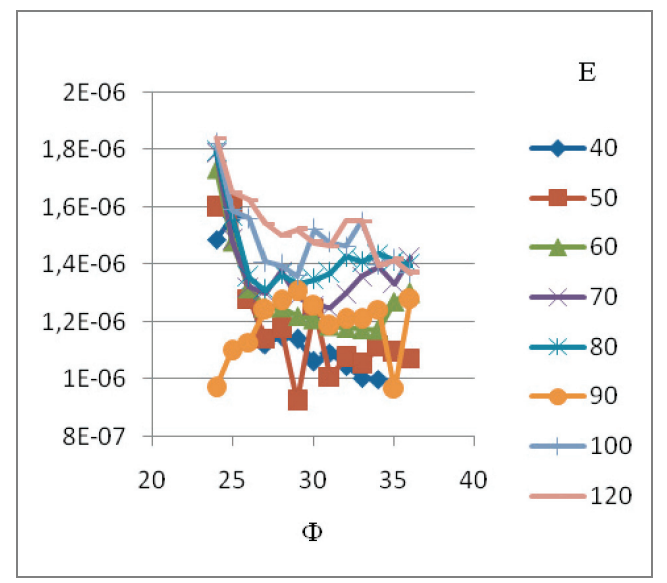

Fig. 12. Graphs of $\Psi_{2}$ function values, site I2

Back analysis calculations for the state of halfway excavation to the depth of $2.0 \mathrm{~m}$ did not produce indisputable values of geotechnical fill parameters for which the minima of functions $\Psi_{1}$ and $\Psi_{2}$ are obtained. For research site I2, the minimum values of functions $\Psi_{1}$ and $\Psi_{2}$ appeared for the lower limit of internal friction angle range $\Phi=24^{\circ}$ and $E=90 \mathrm{MPa}$ or for $\Phi=29^{\circ}$ and $E=90 \mathrm{MPa}$, or for $\Phi=31^{\circ}$ and $E=70 \mathrm{MPa}$. There are also local maxima or minima inside the analysed angle of internal friction range. The influence of Young's modulus on the values of functions $\Psi_{1}$ and $\Psi_{2}$ is more apparent.

It is noticeable that the minima of functions $\Psi_{1}$ and $\Psi_{2}$ for a $2.0 \mathrm{~m}$ deep excavation are observed for higher values of internal friction angle than in the case of a $4.0 \mathrm{~m}$ deep excavation.

This proves the loosening of soil resulting from the pile wall displacement during excavation deepening.

\section{CONCLUSIONS}

The presented analyses of inclinometer measurements and calculations, as well as methods of interpreting horizontal displacements of excavation shoring structures demonstrate that the values of calculated support displacements depend on numerous factors including adopting the appropriate parameter values and the appropriate model of soil medium. For the case discussed, the geotechnical parameters of fill layer calculated by back analysis turned out to be worse than the parameters adopted initially for design calculations. 
A distinct minimum of the objective function defined by back analysis was observed for a $4.0 \mathrm{~m}$ deep excavation. For a $2.0 \mathrm{~m}$ deep excavation, the results of back analysis are disputable.

The measured horizontal displacements of excavation supporting structure assumed different values at the two inclinometer sites analysed. Back analysis results for these sites are approximately convergent for a $4.0 \mathrm{~m}$ deep excavation.

Comparing relative displacements from inclinometer measurements is more reliable due to the unambiguity of their results. However, this does not display the actual deflection curve and the character of wall displacement, especially at its base. These two aspects are better represented by numerical calculations.

Static analysis of the system composed of a pile wall and the interacting soil, carried out by means of finite element method using an elastic-perfectly plastic soil model with Coulomb-Mohr yield condition, is the appropriate tool for displacement calculation. The soil model combines a simplicity in estimating and obtaining its parameters with the accuracy of inclinometer measurement results.

\section{REFERENCES}

[1] Bui H.D., TANAKa M., Inverse problems in engineering mechanics, Balkema, Paris, France, 1994.

[2] Calvello M., Finno R.J., Calibration of soil models by inverse analysis, Proc. Int. Symposium on Numerical Models in Geomechanics, NUMOG VIII, Balkema, Rotterdam, The Netherlands, 2002, $107-116$.

[3] Calvello M., FinNo R.J., Selecting parameters to optimize in model calibration by inverse analysis, Comput. Geotech., 2004, 31 (5), 411-425.

[4] Clough G.W., O'Rourke T.D., Construction induced movements of in situ walls, Proc., Conf. on Design and Performance of Earth Retaining Structures, ASCE, Geotechnical Special Publication, No. 25, ASCE, New York, 1990, 439-470.

[5] DunNiclifF J., Geotechnical Instrumentation for Monitoring Field Performance, Wiley, New York, 2004.

[6] DyBicz R., SiEMiŃSKA-LewANDOwsKA A., Analiza współpracy grunt-konstrukcja oporowa na podstawie pomiarów w warunkach rzeczywistych, Inżynieria i Budownictwo, 2010, No. 11.

[7] Inclinometers. Instruction manual. (09/05-Rev.4).

[8] Incli2 User's Manual. Realese 4.0 - July 2006.

[9] JANUSZ J., Inklinometr cięgnowy do pomiaru przemieszczeń poziomych, Inżynieria i Budownictwo, 1999, No. 7-8, s. 452.

[10] KŁOSIŃSKI B., Wpływ głębokich wykopów na odksztatcenia przyległych obiektów budowlanych, Inżynieria i Budownictwo, 2010, 11.

[11] Ledesma A., Gens A., Alonso E.E., Estimation of parameters in geotechnical back analysis. I. Maximum likelihood approach, Computers and Geotechnics, 1996, 18, 1, 1-27.

[12] LONG M., Database for retaining wall and ground movements due to deep excavations, Journal of Geot. \& Geoenv. Eng., 2001, No. 3.

[13] SRokosz P., Back analysis inverse problems in geotechnics-examples of shape determination, Foundations of Civil and Enviromental Engineering, 2008, No. 8. 
[14] Vermeer P.A., Plaxis. Delft University of Technology, A.A. Balkema, Netherlands, 1994.

[15] VAIRAKTARIS E., Inverse problems in geomechanics, European Journal of Environmental and Civil Engineering, 2010, Vol. 14, Iss. 8-9.

[16] Youssef M.A., Hashash Séverine Levasseur, Abdolreza Osouli, Richard Finno, Yann MALECOT, Comparison of two inverse analysis techniques for learning deep excavation response, Computers and Geotechnics, 2010, Vol. 37, Iss. 3, 323-333. 